\title{
Effect of plant growth regulators on the accumulation of indolizidine alkaloids in Securinega suffruticosa callus cultures
}

\author{
Danuta Raj $^{1}$ - Adam Kokotkiewicz ${ }^{2}$ Andrzej Drys ${ }^{3} \cdot$ Maria Luczkiewicz $^{2}$
}

Received: 23 February 2015/ Accepted: 19 June 2015/Published online: 29 June 2015

(c) The Author(s) 2015. This article is published with open access at Springerlink.com

\begin{abstract}
In the presented work, plant growth regulators (PGRs) were tested for their influence on biomass growth and accumulation of therapeutically-relevant indolizidine alkaloids in Securinega suffruticosa (Phyllanthaceae) callus cultures. The study included 9 auxins [2,4-dichlorophenoxyacetic acid (2,4-D), 2,4,5-trichlorophenoxyacetic acid, indole-3-acetic acid (IAA), 4-chlorophenoxyacetic acid, indole-3-butyric acid, 4-amino-3,5,6-trichloropicolinic acid, $\beta$-naphthoxyacetic acid, 1-naphthaleneacetic acid, indole-3propionic acid, one polar auxin transport inhibitor $(2,3,5$ triiodobenzoic acid) and 7 cytokinins [2-isopentenyladenine, 1-phenyl-3-(1,2,3-thiadiazol-5-yl)urea, $N$-(2-chloro-4-pyridinyl)- $N^{\prime}$-phenylurea, diphenylurea, zeatin, kinetin (KIN), 6-benzylaminopurine]. The respective PGRs were applied at 0.5 and $5.0 \mathrm{mg} \mathrm{l}^{-1}$, together with 5.0 or $0.5 \mathrm{mg} \mathrm{l}^{-1} \mathrm{KIN}$ or 2,4-D (for auxins and cytokinins, respectively). The calli subjected to different phytohormone combinations (39 modifications in total) were evaluated for growth and alkaloid content, and the results tested for statistical differences. The highest concentrations of securinine $\left(1.73 \mathrm{mg} \mathrm{g}^{-1} \mathrm{DW}\right)$ and allosecurinine $\left(3.11 \mathrm{mg} \mathrm{g}^{-1} \mathrm{DW}\right)$ were recorded in the callus grown in the presence of $0.5 \mathrm{mg} \mathrm{L}^{-1} \mathrm{IAA}$ and
\end{abstract}

Maria Luczkiewicz

mlucz@gumed.edu.pl

1 Department of Pharmacognosy, Faculty of Pharmacy, Wroclaw Medical University, ul. Borowska 211 A, 50-556 Wrocław, Poland

2 Department of Pharmacognosy, Faculty of Pharmacy, Medical University of Gdansk, al. gen. J. Hallera 107, 80-416 Gdańsk, Poland

3 Department of Physical Chemistry, Faculty of Pharmacy, Wroclaw Medical University, ul. Borowska 211 A, 50-556 Wrocław, Poland
$5.0 \mathrm{mg} \mathrm{L}^{-1} \mathrm{KIN}$. To the best of the authors' knowledge, this is the first such comprehensive report concerning the influence of PGRs on alkaloid accumulation in plant in vitro cultures.

Keywords Indolizidine alkaloids - Securinine - Auxins · Cytokinins · Phyllanthaceae

\begin{tabular}{|c|c|}
\hline \multicolumn{2}{|c|}{ Abbreviations } \\
\hline AS & Allosecurinine \\
\hline BAP & 6-Benzylaminopurine \\
\hline 4-CPA & 4-Chlorophenoxyacetic acid \\
\hline CPPU & $\begin{array}{l}N \text {-(2-chloro-4-pyridinyl)- } N^{\prime} \text {-phenylurea } \\
\text { (forchlorfenuron) }\end{array}$ \\
\hline 2,4-D & 2,4-Dichlorophenoxyacetic acid \\
\hline DPU & Diphenylurea \\
\hline DW & Dry weight \\
\hline $\mathrm{G}_{\mathrm{i}}$ & Growth index \\
\hline HPTLC & High performance thin layer chromatography \\
\hline IAA & Indole-3-acetic acid \\
\hline IBA & Indole-3-butyric acid \\
\hline $2 \mathrm{iP}$ & $\begin{array}{l}\text { 6- }(\gamma, \gamma \text {-Dimethylallylamino)purine } \\
\text { (2-isopentenyladenine) }\end{array}$ \\
\hline IPA & Indole-3-propionic acid \\
\hline KIN & Kinetin \\
\hline NAA & 1-Naphthaleneacetic acid \\
\hline BNOA & $\beta$-Naphthoxyacetic acid \\
\hline PGR & Plant growth regulator \\
\hline PCL & 4-Amino-3,5,6-trichloropicolinic acid (picloram) \\
\hline $\mathrm{S}$ & Securinine \\
\hline $\mathrm{SH}$ & Schenk-Hildebrandt \\
\hline $2,4,5-\mathrm{T}$ & 2,4,5-Trichlorophenoxyacetic acid \\
\hline TDZ & $\begin{array}{l}\text { 1-Phenyl-3-(1,2,3-thiadiazol-5-yl)urea } \\
\text { (thidiazuron) }\end{array}$ \\
\hline TIBA & 2,3,5-Triiodobenzoic acid \\
\hline ZEA & Zeatin \\
\hline
\end{tabular}




\section{Introduction}

Securinine (S), the main pharmacologically active constituent of Securinega suffruticosa (Pall.) Rehd., Phyllanthaceae, is an indolizidine alkaloid and $\gamma$-aminobutyric $\operatorname{acid}_{A}$ receptor $\left(G_{A B A} R\right)$ competitive antagonist. $S$ is considered a promising agent for the prevention and treatment of neurodegenerative diseases, including Alzheimer's disease, amyotrophic lateral sclerosis and post-alcohol degeneration (Raj and Luczkiewicz 2008; Gupta et al. 2011). Apart from the above properties, $S$ was shown to exhibit cytotoxic activity against colon (Rana et al. 2010) and breast cancer cell lines (Li et al. 2014), as well as inhibit toxoplasma growth (Holmes et al. 2011). The second main alkaloid of $S$. suffruticosa, allosecurinine (AS), acts as a cholinergic agent (Raj and Luczkiewicz 2008).

In previous years, in vitro cultures of $S$. suffruticosa were established in order to provide an efficient and reliable source of securinega alkaloids (Wysokińska 1979; Ide et al. 1986; Ide 1991; Yuan et al. 2005, 2007; Raj et al. 2009, 2015). Despite promising results in terms of alkaloid accumulation, these reports provided limited data on the influence of phytohormones on the accumulation of $\mathrm{S}$ and related compounds in the investigated biomasses. Given that the biosynthesis of alkaloids in plant cell cultures is strongly affected by both the type and concentration of PGRs used (Verpoorte et al. 1991), modifications of phytohormone composition can be considered a simple, yet effective tool for improving the productivity of an in vitro system. However, contrary to other alkaloid groups such as indole (Verpoorte et al. 1991; van der Heijden et al. 2004; Pietrosiuk et al. 2007) and diterpene derivatives (Sabater-Jara et al. 2010; Malik et al. 2011), reports concerning the influence of exogenous PGRs on indolizidine alkaloid accumulation are rather scarce and limited to the most commonly used phytohormones like 2,4-dichlorophenoxyacetic acid (2,4-D), 1-naphthaleneacetic acid (NAA), and kinetin (KIN) (Wysokińska 1979; Ide 1991; Yuan et al. 2007).

The aim of the presented work was to investigate the influence of different combinations of PGRs (39 modifications in total) on biomass growth and the accumulation of $\mathrm{S}$ and AS in S. suffruticosa callus cultures. Consequently, the experiment led to the selection a phytohormone composition providing the highest concentrations of the investigated compounds. Correlations between callus growth and the accumulation of indolizidine alkaloids were established and possible relationships between the chemical structure of the PGRs used and the observed effects were also discussed. To the authors' knowledge, this is the first such comprehensive study on the influence of phytohormones on alkaloid accumulation in a single in vitro model.

\section{Materials and methods}

\section{Plant material}

The experiments were conducted with the use of previously established (Raj et al. 2009) S. suffruticosa callus cultures, grown on solidified $(0.7 \%$ w/v agar) Schenk-Hildebrandt (SH) medium (Schenk and Hildebrandt 1972) containing $5.0 \mathrm{mg} \mathrm{l}^{-1}$ 2,4-D, $5.0 \mathrm{mg} \mathrm{l}^{-1} \mathrm{KIN}$ and $3 \% \mathrm{w} / \mathrm{v}$ sucrose, and subcultured at 4 -week intervals.

\section{Experimental procedures and culture conditions}

For the experiment, $1 \mathrm{~g}$ portions of $S$. suffruticosa callus, taken on $30 \mathrm{~d}$ of the growth cycle, were transferred to baby food jars (Sigma-Aldrich, St. Louis, US-MO) filled with $25 \mathrm{ml}$ of the solidified $(0.7 \% \mathrm{w} / \mathrm{v}$ agar $)$ SH media supplemented with $3 \%(\mathrm{w} / \mathrm{v})$ sucrose and the respective phytohormones (10 replicates per modification, 2 series of 5 repetitions). The cultures were maintained at $24 \pm 1{ }^{\circ} \mathrm{C}$ under a 16/8 (light/dark) photoperiod $\left(88 \pm 8 \mu \mathrm{mol} \mathrm{m}{ }^{-2} \mathrm{~s}^{-1}\right.$, Philips TLD 35 fluorescent lamps). After 4 -weeks, the calli were harvested and their growth indices $(\mathrm{Gi})$ calculated as described by Yuan et al. (2007). After freeze-drying (Lyovac GT2, Fin-Aqua-Santasalo-Sohlberg Co, Tuusula, Finland), the samples were evaluated for S and SA content using the previously developed HPTLC-densitometric method (Raj et al. 2009).

PGRs used in the study were either sterile-filtered [forchlorfenuron (CPPU), diphenylurea (DPU), indole-3acetic acid (IAA), 2-isopentenyladenine (2iP), thidiazuron (TDZ), 2,3,5-triiodobenzoic acid (TIBA); Schleicher \& Schuell $0.2 \mu \mathrm{m}$ CA filters, GE Healthcare, Little Chalfont, $\mathrm{UK}]$ into the pre-autoclaved media or co-autoclaved (1 bar, $120{ }^{\circ} \mathrm{C}, 20 \mathrm{~min}$ ) with other media components (all reagents from Sigma-Aldrich, purified water produced by double distillation). The $\mathrm{pH}$ of the media was adjusted to 5.8 prior to autoclaving.

\section{Experimental scheme}

In order to test the effect of auxins and anti-auxins on the growth rate and accumulation of S and AS, the KIN-containing media were supplemented interchangeably with 2,4-D, IAA, NAA, TIBA, 4-chlorophenoxyacetic acid (4-CPA), indole-3-butyric acid (IBA), indole-3-propionic acid (IPA), $\beta$-naphthoxyacetic acid (BNOA), 2,4,5trichlorophenoxyacetic acid $(2,4,5-\mathrm{T})$ and picloram (PCL). The respective PGRs and KIN were applied at both 1:10 and $10: 1$ ratio- the media containing 5.0 or $0.5 \mathrm{mg} \mathrm{l}^{-1}$ KIN were supplemented with 0.5 or $5.0 \mathrm{mg} \mathrm{l}^{-1}$ auxin/ auxin inhibitor, respectively. S. suffruticosa calli grown on 
SH media supplemented solely with 0.5 or $5.0 \mathrm{mg} \mathrm{l}^{-1} \mathrm{KIN}$ ( $\mathrm{C} 1$ and $\mathrm{C} 2$, respectively) and the callus maintained on PGR-free SH medium (C0) were the reference groups.

Analogously, the influence of cytokinins on callus growth and the accumulation of the indolizidine alkaloids was investigated by enriching the 2,4-D-supplemented media interchangeably with CPPU, DPU, 2iP, KIN, TDZ, 6-benzylaminopurine (BAP) and zeatin (ZEA). The cytokinins and 2,4-D were applied at both 1:10 and 10:1 ratiothe media containing 5.0 or $0.5 \mathrm{mg} \mathrm{l}^{-1} 2,4$-D were supplemented with 0.5 or $5.0 \mathrm{mg} \mathrm{l}^{-1}$ auxins, respectively. $S$. suffruticosa calli grown on SH media supplemented solely with 0.5 or $5.0 \mathrm{mg} \mathrm{l}^{-1}$ 2,4-D (C3 and $\mathrm{C} 4$, respectively) and the callus maintained on PGR-free SH medium (C0) were the reference groups.

In the next part of the study, the PGRs which provided the best results in terms of indolizidine alkaloid content (IAA and ZEA of auxin and cytokinin group, respectively) were applied jointly at 1:10 and 10:1 ratio (2 modifications: $0.5 \mathrm{mg} \mathrm{l}^{-1}$ IAA + $5.0 \mathrm{mg} \mathrm{l}^{-1}$ ZEA and $5.0 \mathrm{mg} \mathrm{l}^{-1}$ IAA $+0.5 \mathrm{mg}^{-1}$ ZEA). S. suffruticosa calli grown in the presence of $0.5 \mathrm{mg}^{-1}$ IAA and $5.0 \mathrm{mg} \mathrm{l}^{-1} \mathrm{KIN}$ (modification providing the highest alkaloid concentration in both variable auxin and variable cytokinin groups) and on the PGR-free medium were the reference groups.

\section{Statistical analysis}

The differences in Gi values and S and AS concentrations observed between the calli grown on media with different PGR composition were tested for statistical significance $(p<0.05)$ using the analysis of variance, followed by Tukey's range test (Statistica 10.0 software, StatSoft, Tulsa, US-OK). Correlations between Gi and accumulation of $\mathrm{S}$ and A were also investigated for each of the experiments $(p<0.05)$.

\section{Results}

The effects of different PGR compositions on the growth rate (Gi value) and indolizidine alkaloid content of $S$. suffruticosa callus were presented in Fig. 1. The biomass maintained on the PGR-free medium (C0 modificationFig. 2a) for $30 \mathrm{~d}$ was characterized by relatively low $\mathrm{Gi}$ value $(218 \%)$. AS concentration in the biomass $\left(1.42 \mathrm{mg} \mathrm{g}^{-1} \mathrm{DW}\right)$ was over twofold higher than that of $\mathrm{S}$ (0.61 $\left.\mathrm{mg} \mathrm{g}^{-1} \mathrm{DW}\right)$.

2,4-D added at $0.5 \mathrm{mg}^{-1}$ as the sole PGR (Fig. 1d, C3) significantly stimulated callus growth $(\mathrm{Gi}=471 \%$, over twofold increase compared to $\mathrm{C} 0$ group) but this effect was not observed when $5.0 \mathrm{mg}^{-1}$ concentration was applied (Fig. 1c, C4). 2,4-D decreased the accumulation of S and
AS in a dose-dependent manner, with stronger inhibitory effect at higher concentration.

The addition of 0.5 or $5.0 \mathrm{mg}^{-1} \mathrm{KIN}$ ( $\mathrm{C} 1$ and $\mathrm{C} 2$, respectively, Fig. 1a, b) had no significant effect on callus growth, but significantly increased the accumulation of both alkaloids. No clear dose-related effects were observed, however, lower KIN concentration (C1) favoured AS production $\left(3.12 \mathrm{mg} \mathrm{g}^{-1}\right.$, ca. twofold increase as compared to $\mathrm{C} 0$ (Fig. 1b).

Auxins/anti-auxins at $0.5 \mathrm{mg} \mathrm{l}^{-1}$, applied jointly with $5.0 \mathrm{mg}^{-1} \mathrm{KIN}$, exhibited variable effects on callus growth, ranging from inhibitory (TIBA, NAA) through neutral (IAA, CPA, IBA, IPA) to stimulatory (2,4,5-T, PCL, BNOA, 2,4D). The combination of $0.5 \mathrm{BNOA}$ and $5.0 \mathrm{KIN}$ provided the highest growth rate $(\mathrm{Gi}=502 \%)$ of all PGR modifications (callus depicted in Fig. 2b). None of the auxins supplemented at $0.5 \mathrm{mg} \mathrm{l}^{-1}$ had statistically significant stimulatory effect on $\mathrm{S}$ accumulation, however, IAA, BNOA and IPA significantly increased AS content. 2,4,5-T and IBA had significant negative effect on $\mathrm{S}$ production, whereas PCL and 2,4-D significantly decreased the accumulation of both alkaloids (Fig. 1a). The highest mean concentrations of $\mathrm{S}$ and AS (1.73 and $3.11 \mathrm{mg} \mathrm{g}^{-1} \mathrm{DW}$ ) were recorded for the culture supplemented with $0.5 \mathrm{mg} \mathrm{l}^{-1}$ IAA and $5.0 \mathrm{mg} \mathrm{l}^{-1}$ KIN (Fig. 1a). Statistical analysis showed negative correlations between callus growth (Gi) and AS concentration $(-0.27, p=0.007)$, as well as between $\mathrm{Gi}$ and the sum of alkaloids $(-0.25, p=0.013)$.

The inclusion of $5.0 \mathrm{mg} \mathrm{l}^{-1}$ auxin into the $0.5 \mathrm{mg} \mathrm{l}^{-1}$ KIN-supplemented medium either did not affect $(2,4,5-\mathrm{T}$, IAA, IBA, PCL, IPA, 2,4-D) or significantly stimulated callus growth (4-CPA, BNOA, NAA). The only exception was the anti-auxin TIBA which at $5.0 \mathrm{mg} \mathrm{l}^{-1}$ significantly decreased the growth rate. As in the case of $0.5 \mathrm{mg} \mathrm{l}^{-1}$ auxin/5.0 $\mathrm{mg}^{-1}$ KIN modifications, the highest Gi value $(490 \%)$ was recorded for BNOA (callus depicted in Fig. 2c). Of the PGRs tested, IAA, IBA, TIBA, BNOA and IPA had no effect on $S$ accumulation whereas 2,4,5-T, 4-CPA, PCL, NAA and 2,4-D exerted significant inhibitory effect. Except for IAA and IPA, AS concentrations in the examined calli were significantly lowered in comparison to reference culture (C1). The combination of $5.0 \mathrm{mg} \mathrm{l}^{-1}$ IAA and $0.5 \mathrm{mg}^{-1} \mathrm{KIN}$ provided the highest mean concentrations of $\mathrm{S}\left(1.42 \mathrm{mg} \mathrm{g}^{-1} \mathrm{DW}\right)$ and AS (2.42 $\left.\mathrm{mg} \mathrm{g}^{-1} \mathrm{DW}\right)$. The statistical analysis showed no important correlations between the growth rate $(\mathrm{Gi})$ and indolizidine alkaloid accumulation.

As depicted in Fig. 1c, cytokinins at $0.5 \mathrm{mg} \mathrm{l}^{-1}$, applied together with $5.0 \mathrm{mg} \mathrm{l}^{-1}$ 2,4-D, had inhibitory (TDZ, CPPU), neutral (2iP, ZEA, KIN, BAP) or stimulatory (DPU, $\mathrm{Gi}=427 \%$ ) effect on callus growth, as compared to C4 reference group (2,4-D only). All the cytokinins tested at $0.5 \mathrm{mg} \mathrm{l}^{-1}$ significantly increased $\mathrm{S}$ 

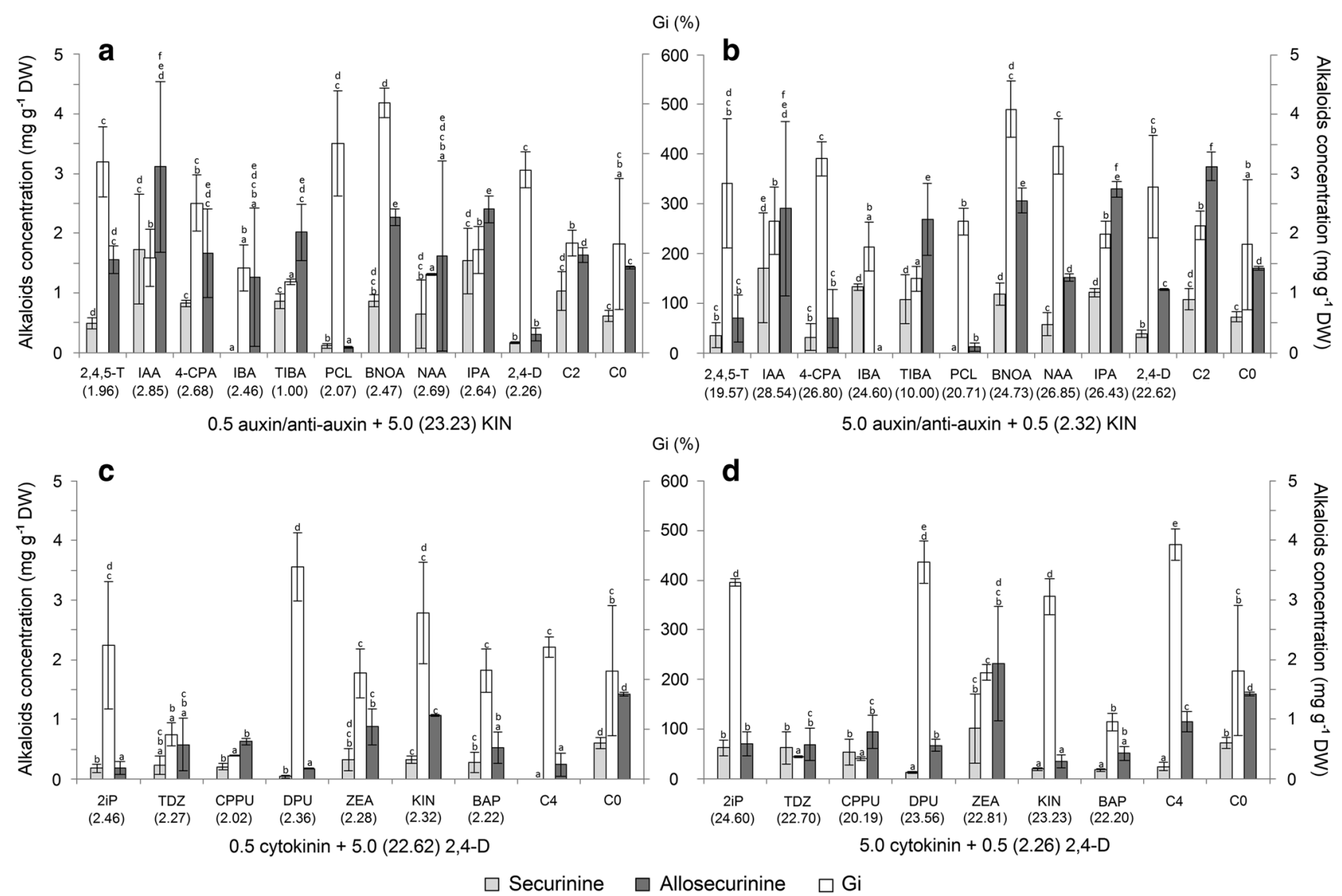

Fig. 1 The effect of different combinations of auxins/anti-auxins and cytokinins on the growth rate $(\mathrm{Gi})$ and indolizidine alkaloid content of S. suffruticosa callus: a $0.5 \mathrm{mg} \mathrm{l}^{-1}$ auxin/anti-auxin $+5.0 \mathrm{mg} \mathrm{l}^{-1}$ $\mathrm{KIN}$, b $5.0 \mathrm{mg}^{-1}$ auxin/anti-auxin $+0.5 \mathrm{mg}^{-1} \mathrm{KIN}$, c $0.5 \mathrm{mg} \mathrm{l}^{-1}$ cytokinin $+5.0 \mathrm{mg} \mathrm{l}^{-1} 2,4-\mathrm{D}, \mathbf{d} 5.0 \mathrm{mg} \mathrm{l}^{-1}$ cytokinin $+0.5 \mathrm{mg} \mathrm{l}^{-1}$

2,4-D (micromolar concentrations are given in parentheses). Control groups: $C O$ phytohormone-free medium, $C 10.5 \mathrm{mg} \mathrm{l}^{-1} \mathrm{KIN}, C 2$ $5.0 \mathrm{mg} \mathrm{l}^{-1}$ KIN, C3 $0.5 \mathrm{mg} \mathrm{l}^{-1} \quad 2,4-\mathrm{D}, C 4 \quad 5.0 \mathrm{mg} \mathrm{l}^{-1} \quad$ 2,4-D. Different letters indicate significant differences between means $(p<0.05)$

accumulation. The same effect was observed for AS, except for 2iP and DPU which had no significant effect on its concentration. The highest amounts of $\mathrm{S}$ and AS were recorded in the calli grown in the presence of $0.5 \mathrm{mg}^{-1}$ ZEA $\left(0.32\right.$ and $0.88 \mathrm{mg} \mathrm{g}^{-1} \mathrm{DW}$, respectively) or $0.5 \mathrm{mg} \mathrm{l}^{-1} \mathrm{KIN}$ (0.32 and $1.06 \mathrm{mg} \mathrm{g}^{-1} \mathrm{DW}$, respectively). At the same time, all phytohormone modifications tested provided lower indolizidine alkaloid concentrations compared to the PGR-free (C0) medium (Fig. 1c). No statistically significant correlations between callus growth and alkaloid concentrations were established.

When supplemented at $5.0 \mathrm{mg} \mathrm{l}^{-1}$ and jointly with $0.5 \mathrm{mg}^{-1} 2,4-\mathrm{D}$, the cytokinins had significant negative effect on callus growth. The inhibitory effect varied from ca. $20 \%(2 \mathrm{iP}, \mathrm{KIN})$ to over $90 \%$ decrease in Gi value recorded for TDZ and CPPU. DPU was the only PGR that did not significantly affect biomass growth $(\mathrm{Gi}=436 \%$, comparable to $\mathrm{C} 3$ group). Of the cytokinins examined, DPU, KIN and BAP had no significant effect on S accumulation, whereas 2iP, TDZ and CPPU caused ca. twofold increase in its concentration. AS accumulation was negatively influenced by $2 \mathrm{iP}$, TDZ, DPU, KIN and BAP but remained statistically unchanged after TDZ and CPPU supplementation. The callus supplemented with $0.5 \mathrm{mg}^{-1}$ ZEA and $5.0 \mathrm{mg}^{-1}$ 2,4-D was characterized by the highest indolizidine alkaloid content $(0.85$ and $1.93 \mathrm{mg} \mathrm{g}^{-1} \mathrm{DW}$ of S and AS, respectively). The obtained results, however, were not significantly different than those of control (C0) group (Fig. 1d). Statistical analysis showed negative correlation $(-0.31, p=0.009)$ between biomass growth (Gi) and $\mathrm{S}$ accumulation, however, no such relationship was established for AS and the sum of alkaloids.

As presented in Fig. 3, the combinations of IAA and ZEA (i.e. the PGRs of auxin and cytokinin groups which provided the highest indolizidine alkaloid accumulationFig. 1) had no significant effect on callus growth. The recorded concentrations of $\mathrm{S}\left(1.02-1.20 \mathrm{mg} \mathrm{g}^{-1} \mathrm{DW}\right)$ and AS (2.00-2.24 $\left.\mathrm{mg} \mathrm{g}^{-1} \mathrm{DW}\right)$ were significantly higher than those in the control group but also significantly lower in comparison to the combination of $0.5 \mathrm{mg} \mathrm{l}^{-1}$ IAA and 

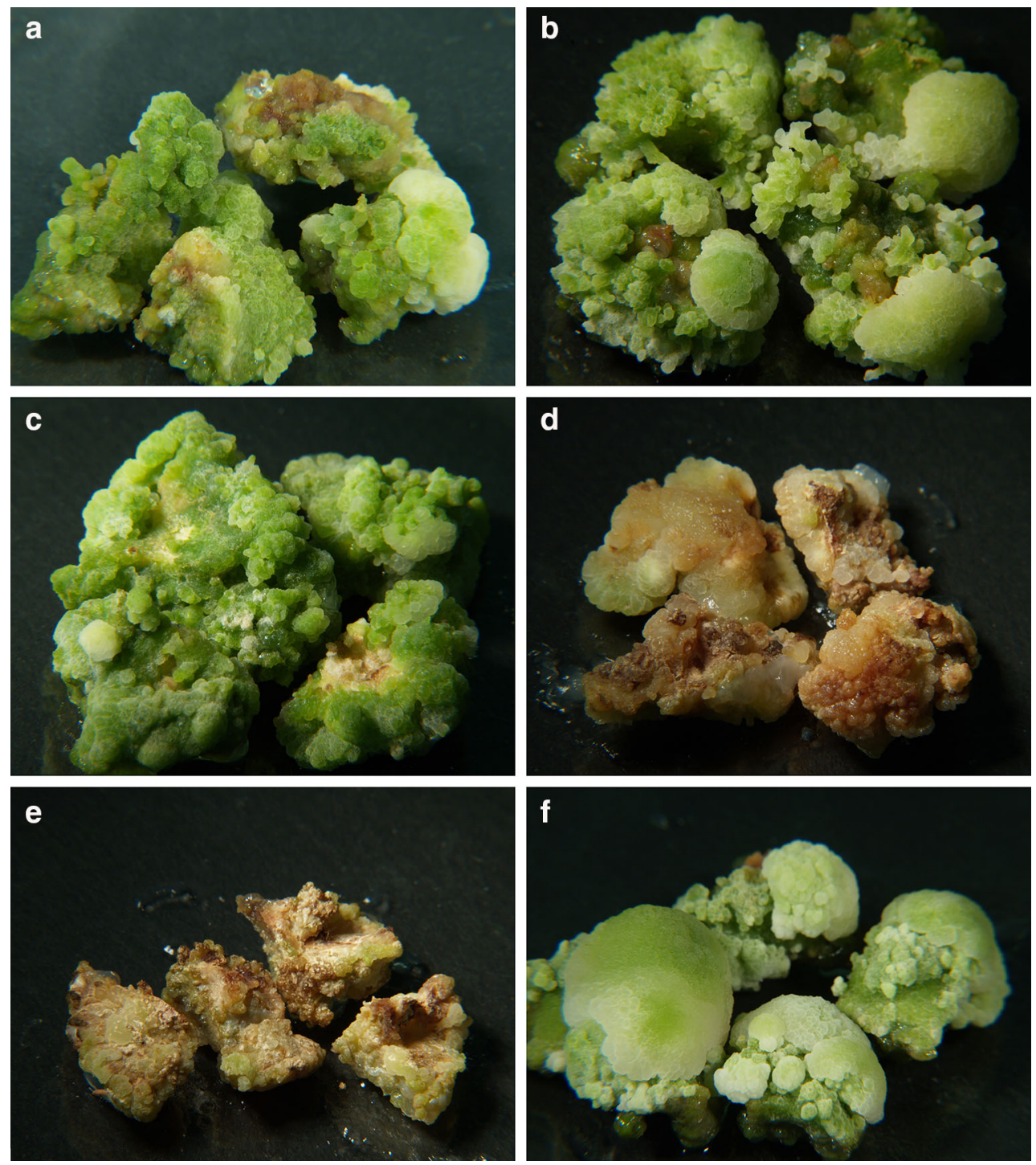

Fig. 2 S. suffruticosa calli grown using different PGR modifications: a PGR-free medium, b $0.5 \mathrm{mg} \mathrm{l}^{-1} \mathrm{BNOA}+5.0 \mathrm{mg} \mathrm{l}^{-1} \mathrm{KIN}$, c $\quad 5.0 \mathrm{mg} \mathrm{l}^{-1} \quad \mathrm{BNOA}+0.5 \mathrm{mg} \mathrm{l}^{-1} \mathrm{KIN}, \quad$ d $0.5 \mathrm{mg} \mathrm{l}^{-1}$

$\mathrm{TDZ}+5.0 \mathrm{mg} \mathrm{l}^{-1} 2,4-\mathrm{D}$, e $5.0 \mathrm{mg} \mathrm{l}^{-1} \mathrm{TDZ}+0.5 \mathrm{mg} \mathrm{l}^{-1} 2,4-\mathrm{D}$, f $0.5 \mathrm{mg} \mathrm{l^{-1 }}$ IAA $+5.0 \mathrm{mg}^{-1} \mathrm{KIN}$

$5.0 \mathrm{mg} \mathrm{l}^{-1} \mathrm{KIN}$ which consequently proved to be most effective PGR composition in the whole experiment (1.73 and $3.11 \mathrm{mg} \mathrm{g}^{-1} \mathrm{DW}$ of $\mathrm{S}$ and $\mathrm{AS}$, respectively).

\section{Discussion}

Modifications of phytohormone composition offer wide possibilities of improving cell culture productivity with respect to therapeutically relevant constituents (Murthy et al. 2014). However, difficulties can arise from often opposite effects of auxins and cytokinins towards secondary metabolism. Consequently, in order to provide high productivity, plant cell cultures need to be maintained in two-phase systems or supplemented with a balanced, empirically optimized auxin/cytokinin composition (Verpoorte et al. 1991; Collin 2001; Luczkiewicz and Cisowski 2001; Ramawat and Mathur 2007).

In the presented work, 39 different PGR combinations were tested for their influence on the growth and indolizidine alkaloid content in $S$. suffruticosa callus cultures. Since the growth of $S$. suffruticosa callus was previously shown to be both auxin- and cytokinin dependent (Raj 2011), the experiment was conducted using auxin/cytokinin combinations. Given that the effects of phytohormones on primary and secondary metabolism are usually dose-dependent (Verpoorte et al. 1991; Ramawat and Mathur 2007), the media with opposite auxin/cytokinin ratios were tested - the experimental approach so far successfully applied in the studies concerning phytohormone- 


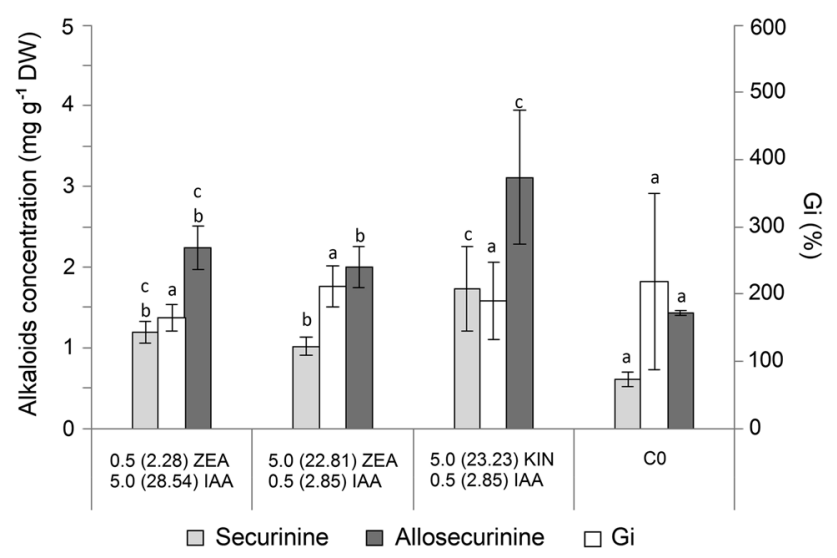

Fig. 3 The effect of the combinations of IAA with ZEA or KIN [concentrations given in $\mathrm{mg}^{-1}$ and $\mu \mathrm{M}$ (values in parentheses)] on the growth rate $(\mathrm{Gi})$ and indolizidine alkaloid content of $S$. suffruticosa callus. C0: phytohormone-free medium. Different letters indicate significant differences between means $(p<0.05)$

related accumulation of phenolics, including anthocyanins (Luczkiewicz and Cisowski 2001), isoflavones (Luczkiewicz et al. 2014) and phenolic acids (Szopa and Ekiert 2014), in plant cell cultures.

When applied alone, 2,4-D and KIN, respectively, had inhibitory and stimulatory effect on alkaloid accumulation which is in agreement with previous studies on cell cultures of alkaloid-bearing plants (Verpoorte et al. 1991; Ramawat and Mathur 2007). The experiments also demonstrated that simultaneous application of KIN and 2,4-D was not beneficial in terms of growth rates and alkaloid concentrations obtained. The influence of different combinations of the above PGRs on the growth and alkaloid content in $S$. suffruticosa callus was also investigated by other authors. Yuan et al. (2007) found that at the constant KIN concentration, the increase in 2,4-D content resulted in slower growth rate and lower alkaloid concentration. In another study, Ide (1991) tested several compositions of 2,4-D and KIN, the best of which yielded $0.06 \mathrm{mg} \mathrm{g}^{-1} \mathrm{~S}$ (compared to $0.32 \mathrm{mg} \mathrm{g}^{-1} \mathrm{~S}$ in the present work). Because of different PGR concentrations applied, the results of previous studies are not directly comparable with the current work. Nevertheless, the general conclusion is that a combination of 2,4-D and KIN can be used for both initiation and maintenance of $S$. suffruticosa cell cultures-while preserving their ability to accumulate alkaloids.

As indicated by previous studies, the replacement of 2,4-D with other auxins often resulted in significant increase of alkaloid accumulation in plant cell cultures (Verpoorte et al. 1991). In the present work, the combination of $0.5 \mathrm{mg} \mathrm{l}^{-1}$ IAA and $5.0 \mathrm{mg} \mathrm{l}^{-1} \mathrm{KIN}$ provided the highest accumulation of $\mathrm{S}$ and AS among all PGR compositions tested. Positive effect on indolizidine alkaloid accumulation was also noted for NAA, confirming the results by Wysokińska (1979), Ide (1991) and Yuan et al. (2007), as well as IPA whose influence on alkaloid metabolism has so far been scarcely investigated.

Contrary to the above PGRs, most auxins included in the study negatively influenced alkaloid accumulation in $S$. suffruticosa, with PCL exhibiting the strongest inhibitory effect. Also, no positive results were found for TIBA, an anti-auxin included in the experiments because of its stimulatory effect on secondary metabolism observed in previous work by the authors (Luczkiewicz et al. 2002, 2014).

When applied at $0.5 \mathrm{mg}^{-1}$, cytokinins were shown to promote alkaloid accumulation in $S$. suffruticosa, thus reversing the negative effect of 2,4-D on secondary metabolism. Nevertheless, the recorded concentrations of $\mathrm{S}$ and AS were still lower than in C0 group (PGR-free medium). In general, media compositions involving purine-type cytokinins (especially ZEA and KIN) had more beneficial effects since they significantly increased alkaloid accumulation without negatively affecting callus growth. Phenylurea derivatives, on the other hand, either inhibited culture growth (TDZ and CPPU) or strongly increased biomass yield at the expense of alkaloid production (DPU).

An important observation arising from the study is that PGR combinations of $0.5 \mathrm{mg} \mathrm{l}^{-1}$ auxin and $5.0 \mathrm{mg} \mathrm{l}^{-1}$ cytokinin employed in the study showed negative correlation between callus growth and alkaloid accumulation, indicating that the growth medium could not be optimized for both high biomass yield and secondary metabolite content. It also needs to be mentioned that several PGRs included in the study (e.g. PCL, TIBA, TDZ, CPPU, CPU) were not previously examined with respect to their influence on indolizidine alkaloid biosynthesis. Therefore, it is difficult to assess whether the observed effects follow a general rule or are rather species-specific.

In the final part of the study, S. suffruticosa calli were grown on the media supplemented with the combinations of auxin and cytokinin which provided the highest indolizidine alkaloid content (IAA and ZEA, respectively) in order to check for synergistic effects between both PGRs. The experiment proved unsuccessful, yielding lower concentrations of S and AS compared to IAA/KIN composition. Nevertheless, the maximum securinine content obtained in the present work $\left(1.73 \mathrm{mg} \mathrm{g}^{-1} \mathrm{DW}\right)$ was higher in comparison to the reports by Wysokińska (1979) and Ide (1991) (1.17 and $0.4 \mathrm{mg} \mathrm{g}^{-1} \mathrm{DW}$, respectively).

\section{Conclusions}

Cell growth and securinine concentration in S. suffruticosa callus cultures proved to be strongly affected by the type and amount of the PGRs applied. Of the phytohormone 
compositions tested, the highest indolizidine alkaloid content was achieved using the combination of $0.5 \mathrm{mg}^{-1}$ IAA and $5.0 \mathrm{mg} \mathrm{l}^{-1} \mathrm{KIN}$, providing higher securinine concentration in comparison to previous reports. However, negative correlation between callus growth and indolizidine alkaloid accumulation indicates that developing a two-phase production system may be necessary to further improve alkaloid productivity of $S$. suffruticosa cell cultures.

\section{Compliance with Ethical Standards}

Conflict of interest The authors declare that they have no conflict of interest and the presented work is compliant with ethical standards of Plant Cell, Tissue and Organ Culture. All the authors read and approved the manuscript in its final form.

Open Access This article is distributed under the terms of the Creative Commons Attribution 4.0 International License (http://creativecommons.org/licenses/by/4.0/), which permits unrestricted use, distribution, and reproduction in any medium, provided you give appropriate credit to the original author(s) and the source, provide a link to the Creative Commons license, and indicate if changes were made.

\section{References}

Collin H (2001) Secondary product formation in plant tissue cultures. Plant Growth Regul 34:119-134. doi:10.1023/A:1013374417961

Gupta K, Chakrabarti A, Rana S, Ramdeo R, Roth BL, Agarwal ML, Tse W, Agarwal MK, Wald DN (2011) Securinine, a myeloid differentiation agent with therapeutic potential for AML. PLoS ONE 6:e21203. doi:10.1371/journal.pone.0021203

Holmes M, Crater AK, Dhudshia B, Thadani AN, Ananvoranich S (2011) Toxoplasma gondii: inhibitory activity and encystation effect of securinine and pyrrolidine derivatives on Toxoplasma growth. Exp Parasitol 127:370-375. doi:10.1016/j.exppara.2010. 09.002

Ide A (1991) Securinega suffruticosa: In vitro culture and the formation of securinega alkaloids. In: Bajaj YPS (ed) Biotechnology in agriculture and forestry, vol 15: medicinal and aromatic plants III. Springer, Berlin, pp 420-431. doi:10.1007/ 978-3-642-84071-5_25

Ide A, Fujioka N, Nagano K, Tanaka N, Iwasaki K, Yamane Y, Koga D, Yagishita K, Nakao K, Kurisu Y, Fujioka N, Kohda H, Miyagawa H, Yamasaki K (1986) Growth and alkaloid production of callus culture induced from Securinega suffruticosa. Phytochemistry 26:145-148. doi:10.1016/S0031-9422(00)81499-5

Li M, Han S, Zhang G, Wang Y, Ji Z (2014) Antiproliferative activity and apoptosis-inducing mechanism of L-securinine on human breast cancer MCF-7 cells. Pharmazie 69:217-223. doi:10.1691/ ph.2014.3802

Luczkiewicz M, Cisowski W (2001) Optimisation of the second phase of a two phase growth system for anthocyanin accumulation in callus cultures of Rudbeckia hirta. Plant Cell Tiss Organ Cult 65:57-68. doi:10.1023/A:1010652507981

Luczkiewicz M, Zárate R, Dembińska-Migas W, Migas P, Verpoorte R (2002) Production of pulchelin E in hairy roots, callus and suspension cultures of Rudbeckia hirta L. Plant Sci 163:91-100. doi:10.1016/S0168-9452(02)00065-1

Luczkiewicz M, Kokotkiewicz A, Glod D (2014) Plant growth regulators affect biosynthesis and accumulation profile of isoflavone phytoestrogens in high-productive in vitro cultures of Genista tinctoria. Plant Cell Tiss Organ Cult 118:419-429. doi:10.1007/s11240-014-0494-4

Malik S, Cusidó RM, Mirjalili MH, Moyano E, Palazón J, Bonfill M (2011) Production of the anticancer drug taxol in Taxus baccata suspension cultures: a review. Process Biochem 46:23-34. doi:10.1016/j.procbio.2010.09.004

Murthy HN, Lee E-J, Paek K-Y (2014) Production of secondary metabolites from cell and organ cultures: strategies and approaches for biomass improvement and metabolite accumulation. Plant Cell Tiss Organ Cult 118:1-16. doi:10.1007/s11240014-0467-7

Pietrosiuk A, Furmanowa M, Łata B (2007) Catharanthus roseus: micropropagation and in vitro techniques. Phytochem Rev 6:459-473. doi:10.1007/s11101-006-9049-6

Raj D (2011) Badania biotechnologiczne nad akumulacją związków alkaloidowych w kulturach in vitro Securinega suffruticosa, $\mathrm{PhD}$ Thesis, Wroclaw Medical University

Raj D, Luczkiewicz M (2008) Securinega suffruticosa. Fitoterapia 79:419-427. doi:10.1016/j.fitote.2008.02.011

Raj D, Kokotkiewicz A, Luczkiewicz M (2009) Densitometric HPTLC analysis of indolizidine alkaloids in the herb and in vitro cultures of Securinega suffruticosa. J Planar Chromatogr Mod TLC 22:371-376. doi:10.1556/JPC.22.2009.5.11

Raj D, Kokotkiewicz A, Luczkiewicz M (2015) Production of therapeutically relevant indolizidine alkaloids in Securinega suffruticosa in vitro shoots maintained in liquid culture systems. Appl Biochem Biotechnol 175:1576-1587. doi:10.1007/s12010-014-1386-0

Ramawat KG, Mathur M (2007) Factors affecting the production of secondary metabolites. In: Ramawat KG, Merillon JM (eds) Biotechnology: secondary metabolites. CRC Press, Boca Raton, pp 59-102. doi: 10.1201/b10756-4

Rana S, Gupta K, Gomez J, Matsuyama S, Chakrabarti A, Agarwal M, Agarwal A, Agarwal M, Wald D (2010) Securinine induces p73-dependent apoptosis preferentially in p53-deficient colon cancer cells. FASEB J 24:2126-2134. doi:10.1096/fj.09-148999

Sabater-Jara AB, Tudela LR, López-Pérez AJ (2010) In vitro culture of Taxus sp.: strategies to increase cell growth and taxoid production. Phytochem Rev 9:343-356. doi:10.1007/s11101010-9167-z

Schenk RU, Hildebrandt AC (1972) Medium and techniques for induction and growth of monocotyledonous and dicotyledonous plant cell cultures. Can J Bot 50:199-204. doi:10.1139/b72-026

Szopa A, Ekiert H (2014) Production of biologically active phenolic acids in Aronia melanocarpa (Michx.) Elliott in vitro cultures cultivated on different variants of the Murashige and Skoog medium. Plant Growth Regul 72:51-58. doi:10.1007/s10725013-9835-2

van der Heijden R, Jacobs DI, Snoeijer W, Hallard D, Verpoorte R (2004) The Catharanthus alkaloids: pharmacognosy and biotechnology. Curr Med Chem 11:607-628. doi:10.2174/0929867043455846

Verpoorte R, van der Heijden R, van Gulik WM, ten Hoopen HJG (1991) Plant biotechnology for the production of alkaloids: present status and prospects. In: Brossi A (ed) The alkaloids: chemistry and pharmacology, vol 40. Academic Press, San Diego, pp 1-187. doi:10.1016/S0099-9598(08)60268-0

Wysokińska H (1979) Wpływ niektórych regulatorów wzrostu i prekursorów biosyntezy alkaloidów na kultury tkankowe i komórkowe Securinega suffruticosa (Pall.) Rehd., PhD Thesis, Medical University of Lodz

Yuan W, Lu Z, Liu Y, Meng C, Cheng KD, Zhu P (2005) Three new podocarpane-type diterpenoids from callus of Securinega suffruticosa. Chem Pharm Bull 53:1610-1612. doi:10.1248/cpb.53.1610

Yuan W, Zhu P, Cheng K, Meng C, Wu F, Zhu H (2007) Callus of Securinega suffruticosa, a cell line accumulates dextro Securinega alkaloids. Nat Prod Res 21:234-242. doi:10.1080/ 14786410701189781 